\title{
The Effect of Hypermedia-Based e-Book on Learning Achievement of Integral Calculus
}

\author{
Awaludin $^{1}$, Basuki Wibawa ${ }^{2}$, Bintang Petrus Sitepu ${ }^{3}$, Murni Winarsih $^{4}$ \\ \{awaludinrahman78@gmail.com¹, bwibawa_ft@hotmail.com², bpsitepu@ hotmail.com ${ }^{3}$, \\ mwinarsih@unj.ac.id $\left.{ }^{4}\right\}$ \\ Universitas Negeri Jakarta, Jakarta, Indonesia ${ }^{1234}$
}

\begin{abstract}
This study aimed to investigate the effect of hypermedia-based e-book on mathematics students' integral calculus learning achievement. This study was an experimental research with pre- and post-test design. 30 students of Mathematics department at Halu Oleo University participated as the subject in this study. The instruments consisted of the test of integral calculus and observation for students during the integral calculus class. The data were analyzed using descriptive analysis and inferential analysis. The findings show that there is a significant effect of hypermediabased e-book on students' integral calculus achievement. Moreover, It is also found that the students' participation level are high during the integral calculus class.
\end{abstract}

Key words: E-book, Hypermedia, integral calculus learning achievement

\section{Introduction}

Calculus can be defined as a subject that studies the changes ofvariables. Calculus can be applied in areas such as science, economy and engineering. It also can be used to solve various problems that cannot be solved by elementary algebra. Furthermore, calculus is divided into two major parts; differential and integral calculus. Differential calculus includes the calculation of velocities and rates, slopes of curves and optimization while integral calculus application includes width calculation, volume, lengths ofarrow, center mass, performance and pressure. However, it isreported that the students still find it difficult to understand the application of integral concepts in solving problems. In other words, the students cannot use integral calculus concepts to solve problems in relation to mathematics or other daily problems. This is due the fact that integral calculus is a subject which is considered difficult to learn by students (Rahman, 2005). However,there has been a growing interest in intergrating technology into calculus lesson.Awang and Zakaria (2013) conducted a study of integrating maple program in integral calculus lesson. They found that after integrating maple program into calculus lesson, the engineering students showed positive attitude towards calculus subject. Another research was also conducted by Rostislav (2015). His study revealed that students felt happy when they used e-book when learning. In addition, Letchumanan and Tarmizi (2010)investigated mathematics students' attitude at Putra Malaysia University toward use of e-book. The result revealed that the majority of students showed positive attitude towards the use of e-book when doing assignment, as research material and learning material. They also found that e-book has easy navigation (searchable), supported by computer (portable) and easy access which help students learn. 
Nevertheless, the research on the use of e-book hypermedia-based in integral calculus class is still scarce. Therefore, this article will discuss the integral calculus learning achievement of mathematics students at Halu Oleo University before and after the use of hypermedia-based e-book.

\subsection{Research Purpose}

Research Purpose. The purpose of the current study is to investigate the use of hypermediabased e-book as learning material in learning Integral Calculus. Specifically, this study is attempting to (1) describe the students' learning achievement of integral calculus at Mathematics Department; Halu Oleo University after hypermedia-based e-book as learning material was used, (2) to find out the effect of hypermedia-based e-book on students' integral calculus learning achievement at Mathematics department, Halu Oleo University.

\section{Literature Review}

\subsection{Hypermedia-Based e-Book Theory}

Hypermedia-Based e-Book Theory. E-bookcan be defined as an electronic book that has simple format like PDF, EPUB, iBook.Nowadays, e-book can be integrated with various multimedia components such as picture, video, animation into it.The multimedia components enable the learners to learn more easily. E-book with the multimedia components makes learning more interactive, dynamic.Furthermore, the object to belearnt is presented in a more authentic and tangiblemanner (Figueiredo \& Bidarra, 2015; Gorghiua et al, 2014). E-book can be accessed through computer or hand phone that is supported by high resolution and compatible reading devicefor it to be accessed freely (Rahman, 2005; Gorghiua et al, 2014).

Furthermore, e-book with the multimedia components like text, picture, audio, video and animation that are linked is called hypermedia-based e-book. Hypermedia is the linking of several structured multimedia components that enable quick access through navigation system provided (Roblyer \& Doering, 2010; Vaughan, 2011). In other words, hypermedia is the lingking of multimedia documents. Meanwhile multimedia is a combination of text, graphic, arts, sound, animation and video sent to a computer or other electronic devices. This definition emphasizes that interactive multimedia is hypermedia where the user can use navigation system (Himeshet al.,2011).

Hypermedia-based e-book is defined as a digital form of a book based on the elements of learning under learning model that incorporates various multimedia components such as text, picture, video, animation and hyperlink. These components are linked directly so it can be viewed and accessed using personal computer with PDF, HTML and JPEG iBook, animation and video. Interactive components included in an e-book enable learners to give command to the media or answer the questions given (Mishra\&Sharma, 2005).

Moreover, e-bookintegrated with various multimedia components like text, picture, video and animation helps students learn the lesson easier and more authentic. This also improvesconcentration which leads to long lasting knowledge repository. E-book provides easy access and tangibel material which helps students concentrate and achieve high learning outcomes. 
Animation in e-book is in the form of image or object that moves fast and orderly so the image movements show the real object (Elliott \&Hudak, 1997). By looking at the real object, students willfind it easier to understand and comprehend concepts of the object. They will also be able to do a visual representation in their mind which resulted in the object lasts longer in their memory.

E-book can also be integrated with video element. The elements include sound and image. Moreover, through video, the students can learn directly the movement model through observation (Brar \& van der Meij, 2017). Video can also functionas both a support to achieve better learning result and a guidance to finish the task given (Van der Meij, 2017). According to Betrancourt and Benetos (2018), video used in learning process can help developing representation ability, cognitive-perceptual ability and as a learning approach.

Simply put, the presence of multimedia components such as text, image, video and animation ine-books can improve students' motivation and memory retention. In addition, hypermedia components in e-books can improve students' understanding of the material studied. This assuredly can lead to the improvement of students' learning achievement.

\subsection{Learning Achievement}

Learning Achievement. Learning achievement is a change of students' behavior after following learning process. The behavior change includes cognitive, affective and psychomotor aspects. According to Bloom (1956), learning achievement asan education objective can be classified into three parts. They are cognitive, affective and psychomotor aspects. Cognitive domain covers memory and knowledge introduction and development of intellectual ability and thinking skills. Thinking skills are then divided into six levels namely knowledge, comprehension, application, analysis, synthesis and evaluation. Affective domain refers to attitude. Meanwhile psychomotor domain deals with the use of muscle, motoric skills or movement that requires muscle coordination.

Anderson et al. (2008)revised the cognitive dimension proposed by Bloom (1956) by dividing the learning achievement. Cognitive dimension then includes remembering, understanding, applying, analyzing, evaluating and creating. Remembering means retaining the relevant knowledge from long-term memory that consists of recognizing and recalling. Understanding means forming /constructing comprehension of message given during learning process and also communicating it orally, in written and using graphic comprising of interpreting, exemplifying, classifying, summarizing, inferring, comparing, and explaining. Applying is determining or using the procedure in situation given including executing and implementing.

Then, analyzing means dividing the material into parts and determining how the parts can be linked to one another. Analysis includes differentiating, organizing and attributing. Evaluating is giving evaluation based on the criteria or standard provided. Evaluating includes checking and critiquing. Creating refers to putting all the elements together to produce a new form, the coherent unity or create new product. Creating includes generating, planning and producing.

Learning achievement refers to behavior change of a person after going through a process of learning. The change of behavior includes the change of cognitive, affective and psychomotor aspects. Learning achievement dimension that is used as a reference for measuring integral calculus achievement is learning dimension of remembering, understanding, applying, analyzing, evaluating and creating. Integral calculus achievement is a value gained by students after going through the learning process and taking the test of 
mathematics comprising of remembering, understanding, applying, analyzing and creating aspects.

\subsection{Hypermedia-based E-book and Learning Achievement}

Hypermedia-based E-book and Learning Achievement. The students at Mathematics Department of Halu Oleo University were reported to perform poorly due to some limitations associated with integral calculus instruction. These limitations include lack of participation during the lesson, teacher-centered lesson, inappropriate teaching media use and ineffective learning material. The alternative solution to tackle these problems is by developing hypermedia-based e-book learning material for integral calculus class. The advantages of using hypermedia-based e-book include: (1) more interactive learning material integrating links, pictures, video and animation, (2) quick information processing, (3) anywhere and anytime learning opportunity (Letchumanan \& Tarmidzi, 2010). Moreover, there are some more advantages of using hypermedia-based e-book that can be expected. First of all, hypermedia material increases students' motivation by giving the opportunity to be proactive during the learning process. Students are motivated to investigate a problem and try to finish the assignment given by the lecturer quickly. Second of all, students can learn more flexibly. The learning can be done through several ways such as reading texts, looking at pictures or watching animation or video. In other words hypermedia can facilitate students' different learning styles. Furthermore, hypermedia can develop skills of critical and creative thinking. Additionally, hypermedia material can improve students' learning achievement. Using hypermedia-based e-book in integral calculus class enables students to finish the exercise independently. It can also measure students' comprehension level of material designed in the e-book. Hypermedia-based e-book in integral calculus class is designed specifically to assist the interaction between the students, the lecturer and the learning source which will lead to the improvement of integral calculus learning achievement.

\subsection{Research Hypothesis}

It is hypothesized that there is a significant effect of hypermedia-based e-book use on the students' integral calculus learning achievement at Mathematics Department, Halu Oleo University. The hypothesis was tested using inferential analysis through one sample t-test.

\section{Research Method}

The study was an experimental research with the design of pre- and post-test design. The study involved 30 students majoring at Mathematics department of Halu Oleo University. The students were chosen by means of simple random sampling technique. The students wereclassified into high, moderate and low categories. The data was collectedusinga test in the form of multiple choices. The test had been validated and was reliable beforehand. In measuring thetest, correlation product moment was applied. Meanwhile KR-21was employed to measure the test reliability. The data analysis used was descriptive statistics and inferential statistics. The data were analyzed using SPSS program. The descriptive analysis consists of mean, maximum and minimum score, standard deviation and variance. Meanwhile the 
inferential statistic consists of normality data test and mean test of integral calculus using ttest. The research data set can be accessed in osf.io Open Science Framework.

\section{Results and Discussion}

Result. The results on the use of hypermedia-based e-book in integral calculus class shows a significant improvement. The result of descriptive and inferential statistics analysis can be seen in the following table.

Table 1. Description of Integral Calculus Achievement

\begin{tabular}{lll}
\hline Variable & Pretest & Post-test \\
\hline Number of students & 30 & 30 \\
Maximum score & 72 & 96 \\
Minimum Score & 24 & 56 \\
Mean & 44.3 & 77.8 \\
Variance & 174.27 & 116.67 \\
Standard Deviation & 13.2 & 10.8 \\
\hline
\end{tabular}

It can be seen that there is a significant improvement on the students' score. This is supported by the values of both mean scores of 44.3 (pre-test) and 77.8 (post-test).Moreover, the standard deviations of both pre- and post-test are 13.2 and 10.8 respectively.

The inferential statistics is then analysed. Prior to measuring the t-test, the data is analysed to determinethe normality.Normality test is conducted before the t-test. The normality test consists of normality of pre-test and post-test data. The normality data was calculated using SPSS program. The result shows value of sig $=0.721>0.05$. Therefore, it can be concluded that $\mathrm{H} 0$ is accepted. It means that the pre-test data of integral calculus learning result is from normal population. Meanwhile, the test of normality of post-test data shows value of sig $=0.125>0.05$. It can be concluded that $\mathrm{H} 0$ is also accepted. It means that posttest data of integral calculus learning achievement comes from normal population.

After the normality test wasmeasured, then the mean value was analysed using t-test. To obtain the t-test result, the pre- and post-test mean score were analyzed using SPSS. The mean value between pre-test and post-test of integral calculus through paired- sample test shows sig $=0.000<\alpha=0.05$ which means H0 is rejected. It means that there is an effect of hypermediabased e-book on the students ' integral calculus learning achievement at Halu Oleo University.

The results indicate that hypermedia-based e-book enables students to study calculus material by interacting with it.Moreover, e-book has the characteristics of providing intearctive learning materials such as bookmarks, quiz and lab and exercise.These features enable the students to learn the material easily.Moreover, interactive e-books enrich traditional textsby linking them with various multimedia in the forms of image, audio, video and animation. Thus, developing interactive e-book can help facilitatingboth lecturers and students in teaching and learning proess. Through interactive e-book, students can access text, image, animation or video.

Discussion. Additionally, the integral calculus value improved significantly owing to video integrated in the e-book. Students study calculus directly by observing the object being learnt. As a result, the students' integral calculus scores improved significantly. According to Brar 
and Van der Meij (2017),visual representation of the mathematics in the form of video increases students' motivation to learn and improve both comprehension and performance in class. Moreover, videohelps to promote students participation during learning process and increase remembering.Besides, video helps the students to do visual representation or enables students to construct information more accurately in cognitive system (Boucheix, 2018).

Moreover, the improvement of integral calculus learning achievement of mathematics students at Halu Oleo University can be seen in several aspects. Firstly, half of the students were able to determine the width between two curves. Secondly, in measuring the volume of turning object using disc method, the students succedded in doing so owing to the animation feature integrated in the e-book. The animation allows the students to see the visual representation of the object on the curve that is turning around the $\mathrm{x}$ axis until it forms the cone shape. Students found it easier to measure the object volume by looking at the video.Moreover, the video can be played repeteadly.

\section{Conclusion}

Technology has been integrated intothe teaching and learning of mathmatics which greatly benefits the learner. This present study provides the empirical evidence supporting the integration of technology into the teaching and learning of mathmathetics. The result reveals that mean score of post-test is higher than the pre-test $(77.8 \& 44.3$ respectively. It can be inferred that there is a significant effect of hypermedia-based e-book on the integral calculus achievement of mathematics students at Halu Oleo University. 


\section{References}

[1] Anderson, T.: The Teori and Practice of Online Learning $2^{\text {nd }}$ ed. AU Press Canada. Athabasca University. (2008)

[2] Awang, T. S. \& Zakaria, E.: Enhancing Students' Understanding in Integral Calculus through the Integration of Maple in Learning(2013)

[3] Betrancourt, M., \& Benetos, K.: Why and when does instructional videofacilitate learning? A commentary to the special issue "Developments andtrendsinlearningwith instructional video". Computers in Human Behavior (2018)

[4] Bloom, B.S.: Taxonomy of Educational Objectives: The Classification of Educational Goals, Handbook I Cognitive Domain. Longmans, Green and Co, New York(1956)

[5] Boucheix, J.: Developments and Trends in Learning with Instructional Video, Computers in Human Behavior. journal homepage: www.elsevier.com/locate/comphumbeh. https://doi.org/10.1016/j.chb.2018.08.055(2018)

[6] Brar, J., \& van der Meij, H.:Complex software training: Harnessing and optimizing video instruction.Computers inhuman behavior,70, 475485.https://doi.org/10.1016/j.chb.2017.01.014(2017)

[7] Elliott, C \& Hudak, P.: International Conference on Functional Programing. Functional Reactive Animation. Amsterdam Accessed: https://www.eecs.northwestern.edu/ robby/courses/395-4952009-winter/fran.pdf(1997)

[8] Figueiredo, M. \& Bidarra, J.: The development of a Gamebook for education (2015)

[9] Gorghiua, L.M. et al.: The Electronic Book - a Modern Instrument Used in Teacher's Training Process(2014)

[10] Himesh, et al.: Prelimenary Phytochemical Screening And HPLC Analysis Of Flavonoid From Methanolic Extract of Leaves of Annona Squamosa. International Research Journal Of Pharmacy, 2 (5), 242-246 (2011)

[11] Letchumanan, M. and Tarmizi, R.A.: Utilization of E-Book among University Mathematics Students. International Conference on Mathematics Education Research, Procedia Social and Behavioral Sciences 8 pp. 580-587, Elseveir 2010, h.581 (2010)

[12] Mishra, S \& Sharma, R.C.: Interactive Multimedia in education and Training. Idea Group Publishing, Hersey(2005)

[13] Rahman, S.A.:Learning with examples and students' understanding ofMathematics Education, Johor Bahru, Malaysia (2005)

[14] Roblyer, M \& Doering, A.H.: Integrating Educational Technology Into Teaching. Boston: Pearson (2010)

[15] Rostislav, F.: Procedia - Social and Behavioral Sciences 143 pp 342 - 346. Mobile Technologies Education (2014)

[17] Van der Meij, H.: Reviews in instructional video. Computers \& Education. journal homepage: www.elsevier.com/locate/compedu(2017)

[18] Vaughan, T.: Multimedia: Making It Work. 8th Edition. McGraw-Hill, New York (2011) 